\title{
Effects of a chemical chaperone on genetic mutations in $\alpha$-galactosidase A in Korean patients with Fabry disease
}

\author{
Jung-Young Park ${ }^{1}$, Gu-Hwan Kim ${ }^{1,2}$, \\ Sung-Su Kim ${ }^{1}$, Jung Min Ko ${ }^{1,3}$, \\ Jin-Joo Lee ${ }^{2}$ and Han-Wook Yoo ${ }^{1,2,3,4}$ \\ ${ }^{1}$ Genome Research Center for \\ Birth Defects and Genetic Disorders \\ ${ }^{2}$ Medical Genetics Clinic and Laboratory \\ ${ }^{3}$ Department of Pediatrics \\ University of Ulsan College of Medicine \\ Asan Medical Center \\ Seoul 138-736, Korea \\ ${ }^{4}$ Corresponding author: Tel, 82-2-3010-3374; \\ Fax, 82-2-486-3312; E-mail, hwyoo@amc.seoul.kr \\ DOI 10.3858/emm.2009.41.1.001
}

Accepted 22 September 2008

Abbreviations: DGJ, 1-deoxygalatonojirimycin; ERAD, ER-associated degradation; ERP, enzyme replacement therapy; Gb3, globotriaosylceramide; GLA, $\alpha$-galactosidase A; LSD, lysosomal storage disorder

\begin{abstract}
Fabry disease is an X-linked inborn error of glycosphingolipid catabolism that results from mutations in the gene encoding the $\alpha$-galactosidase A (GLA) enzyme. We have identified 15 distinct mutations in the $G L A$ gene in 13 unrelated patients with classic Fabry disease and 2 unrelated patients with atypical Fabry disease. Two of the identified mutations were novel (i.e., the D231G missense mutation and the L268delfsX1 deletion mutation). This study evaluated the effects of the chemical chaperones 1-deoxygalactonojirimycin (DGJ) on the function of GLA in vitro, in cells containing missense mutations in the GLA gene. Nine missense and a nonsense mutations, including one novel mutation were cloned into mammalian expression vectors. After transient expression in COS-7 cells, GLA enzyme activity and protein expression were analyzed using fluorescence spectrophotometry and Western blot analysis, respectively. DGJ enhanced GLA enzyme activity in the M42V, I91T, R112C and F113L mutants. Interestingly, the I91T and $F 113 \mathrm{~L}$ mutations are associated with the atypical form of Fabry disease. However, DGJ treatment did not have any significant effect on the GLA enzyme activity
\end{abstract}

and protein expression of other mutants, including C142W, D231G, D266N, and S297F. Of note, GLA enzyme activity was not detected in the novel mutant (i.e., D231G), although protein expression was similar to the wild type. In the absence of DGJ, the E66Q mutant had wild-type levels of GLA protein expression and approximately $40 \%$ GLA activity, indicating that E66Q is either a mild mutation or a functional single nucleotide polymorphism (SNP). Thus, the results of this study suggest that the chemical chaperone DGJ enhances GLA enzyme activity and protein expression in milder mutations associated with the atypical form of Fabry disease.

Keywords: 1-deoxygalactonojirimycin; Fabry disease; globotriaosylceramide; lysosomal storage diseases; $\alpha$-galactosidase

\section{Introduction}

Fabry disease (OMIM \#301500) is an X-linked recessive lysosomal storage disorder (LSD) caused by deficiency of the $\alpha$-galactosidase A (GLA) enzyme (EC 3.2.1.22). This deficiency results in the systemic accumulation of globotriaosylceramide (Gb3) and related glycosphingolipids in the lysosomes of several different types of cells, including vascular endothelial, smooth muscle, epithelial, perithelial, reticuloendothelial, myocardial, ganglion and perineural cells (Desnick et al., 2001). Early symptoms of Fabry disease include acroparesthesias, angiokeratoma, and corneal opacities (Peter et al., 1997). In elderly patients, glycolipid accumulation can lead to chronic renal failure and stroke. Before the advent of dialysis, transplantation, and enzyme replacement therapy, males afflicted with this disease often died in their fifth decade (Branton et al., 2002).

Mutations in GLA gene cause misfolding, misassembly and aggregation of the protein in the endoplasmic reticulum. Hence, lysosomal trafficking is impaired because the enzyme is retained or degraded by the ubiqutin-proteosome pathway (Frustaci et al., 2001; Yam et al., 2006). However, enzyme activity of the mutant protein can be restored by chemical chaperones, such as galactose and its structural analog, 1-deoxygalactonojirimycin (DGJ) (Okumiya et al., 1995; Fan et al., 1999). 
Table 1. Distribution of mutations in the human GLA gene in Korean patients with Fabry disease.

\begin{tabular}{|c|c|c|c|c|}
\hline \multicolumn{2}{|c|}{ Mutations } & \multirow{2}{*}{ Location } & \multirow{2}{*}{ Phenotype } & \multirow{2}{*}{ Mutagenesis construc } \\
\hline Nucleotide & Amino acids & & & \\
\hline \multicolumn{5}{|l|}{ Missense } \\
\hline c. $124 \mathrm{~A}>\mathrm{G}$ & p.Met42Val & Exon1 & Classical & + \\
\hline c. $196 \mathrm{G}>\mathrm{C}$ & p.Glu66GIn & Exon2 & Classical & + \\
\hline c. $272 T>C$ & p.lle91Thr & Exon2 & Atypical & + \\
\hline c. $334 \mathrm{C}>\mathrm{T}$ & p.Arg112Cys & Exon2 & Classical & + \\
\hline c. $337 \mathrm{~T}>\mathrm{C}$ & p.phe113Leu & Exon2 & Atypical & + \\
\hline c. $426 C>G$ & p.Cys 142Trp & Exon3 & Classical & + \\
\hline$c .692 A>G$ & p.Asp231Gly & Exon5 & Classical & + \\
\hline c.796G $>A$ & p.Asp266Asn & Exon5 & Classical & + \\
\hline c. $890 \mathrm{C}>\mathrm{T}$ & p.Ser297Phe & Exon6 & Classical & + \\
\hline \multicolumn{5}{|l|}{ Nonsense } \\
\hline c. $258 \mathrm{~T}>\mathrm{G}$ & p.Tyr86X & Exon2 & Classical & + \\
\hline c. $1024 \mathrm{C}>\mathrm{T}$ & p.Arg342X & Exon7 & Classical & $\mathrm{N} / \mathrm{A}$ \\
\hline \multicolumn{5}{|l|}{ Deletion } \\
\hline c.296_297del & p.Gln98fsX23 & Exon2 & Classical & $\mathrm{N} / \mathrm{A}$ \\
\hline c.803_806del & p.Leu268delfs X1 & Exon6 & Classical & $\mathrm{N} / \mathrm{A}$ \\
\hline c. $1077 \mathrm{del}$ & p.lle359MetfsX32 & Exon7 & Classical & $\mathrm{N} / \mathrm{A}$ \\
\hline c.1235_1236del & p.Thr412SerfsX38 & Exon7 & Classical & $\mathrm{N} / \mathrm{A}$ \\
\hline
\end{tabular}

Italicized, bolded text refers to the novel mutant identified in the study. The mutations were described according to established mutation nomenclature (http://www.hgvs.org/mutnomen). NM_000169.1 (GenBank) was used as a reference sequence. The +1 notation corresponds to the A of the ATG translation initiation codon. N/A, not applicable.

These chemical chaperones bind to the active site of GLA to promote proper folding and stabilization of the protein (Frustaci et al., 2001). However, the efficacy of chemical chaperones is limited in patients with atypical Fabry disease, and these chaperones are ineffective for most patients with the classic form of the condition (Okumiya et al., 1995; Matsuzawa et al., 2005). The GLA protein is encoded by the GLA gene, which consists of 7 exons on chromosome Xq22.1 (Kornerich et al., 1989). In humans, GLA is synthesized as a $50 \mathrm{kDa}$ precursor, which is further processed to a $46 \mathrm{kDa}$ mature form of the protein (Lenmansky et al., 1987; Froissart et al., 2003). To date, more than 350 mutations have been identified in the human GLA gene. We screened the GLA genes in Korean patients with Fabry disease and identified 15 different mutations, two of which were novel. Also, this study was undertaken to evaluate the effects of the chemical chaperones DGJ on the function of GLA in vitro, in nine groups of cells containing distinct missense mutations in the GLA gene.

\section{Results}

\section{Identification of mutations in the human GLA gene}

We identified 15 mutations in the unrelated Korean probands with Fabry disease. Of these, 9 were

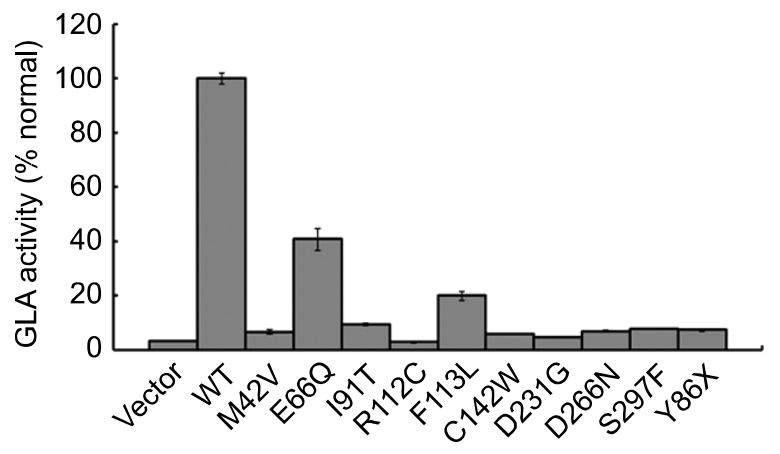

Figure 1. GLA enzyme activity analysis. Mutants were cultured in the absence of chemical chaperone for 2 days before enzyme assays for basal GLA activity. The mean of each standard deviation was calculated from five independent experiments.

missense mutations and 6 nonsense or deletion mutations (Table 1). Two (i.e., D231G and L268delfsX1) were novel mutations, which were not observed in any of the 50 healthy Korean individuals.

\section{Enzyme activity of the GLA mutants}

Constructs that each contained one of 9 distinct missense and a nonsense mutations of GLA were over-expressed in COS-7 cells to verify that the mutants disrupted enzyme activity. The nonsense mutation was used as a negative control. After the 
mutant constructs were transiently over-expressed in the absence of a chemical chaperone, GLA enzyme activity was measured (Figure 1). Enzyme activities of the $E 66 Q$ and $F 113 L$ mutants were approximately $40 \%$ and $20 \%$ lower than that of the wild type, respectively. No residual enzyme activity was detected in the other mutants.

\section{Effects of DGJ on enzyme activity}

To evaluate the effects of the chemical chaperone DGJ, we analyzed GLA enzyme activity and protein expression in mutants cultured in medium containing DGJ for $48 \mathrm{~h}$ (Figure 2). In the presence of $20 \mu \mathrm{M}$ DGJ, the GLA activity of the mutants was similar to that observed in cells cultured without

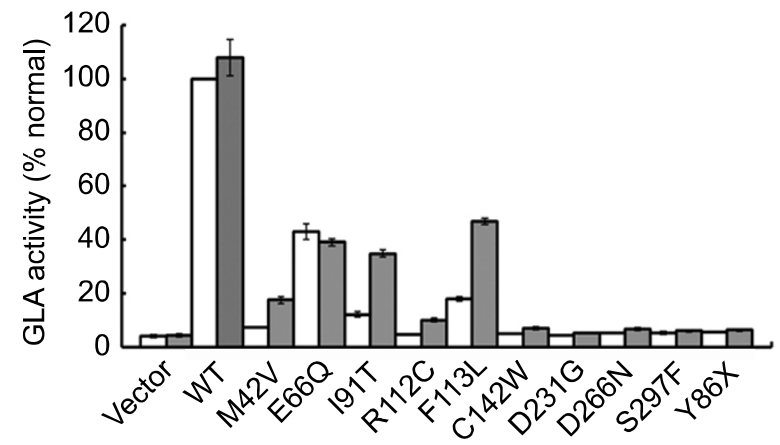

Figure 2. Effect of DGJ on activity of GLA. Mutants were cultured in the presence or absence of $20 \mu \mathrm{M}$ DGJ for 2 days prior to GLA activity assay. The mean of each standard deviation was calculated from five independent experiments. Open bars indicate the absence of DGJ; solid bars indicate the presence of DGJ.
DGJ. As shown in Figure 2 and Table 2, GLA activity was enhanced about 2-3 fold in the M42V $(P<0.0001)$, 191T $(P<0.0001), \quad \mathrm{R} 112 \mathrm{C} \quad(P<$ $0.0001)$ and F113L $(P<0.0001)$ mutants, but enzyme activity of the other mutants was not affected by the addition of DGJ.

\section{Protein expression in the GLA mutants}

Western analyses revealed that GLA was expressed as a $46 \mathrm{kDa}$ protein in COS-7 cells expressing either wild type GLA or the E66Q mutant, indicating that the mature form of GLA was present. In contrast, a $50 \mathrm{kDa}$ protein corresponding to the immature form of GLA was identified in several other mutants. In particular, the D231G mutant yielded both the $50 \mathrm{kDa}$ and $46 \mathrm{kDa}$ forms of the GLA protein, although catalytic activity of GLA was absent (Figure 3A). Also, although the D266N was missense mutation, neither form of the GLA protein was identified (Figure $3 A$ ). To certify this result, pEGFP-C1 vector tagged GFP were co-transfected with the $\mathrm{D} 266 \mathrm{~N}$ mutant in the COS-7 cells. As shown in Figure 3B, GFP protein was detected in both WT and D266N, but GLA protein was not detected in the $\mathrm{D} 266 \mathrm{~N}$ mutant. Furthermore, to evaluate the effects of the chemical chaperone DGJ, we analyzed GLA protein expression in mutants cultured in medium containing DGJ for $48 \mathrm{~h}$ (Figure 3A). In Western analyses, expression of the mature GLA protein increased in the presence of $20 \mu \mathrm{M}$ DGJ in the 191T and $F 113 \mathrm{~L}$ mutants. A marked increase was observed in the F113L mutant, while a much smaller increase was observed in the I91T mutant.

Table 2. Enhancement of GLA activity in COS7 cells cultured with DGJ.

\begin{tabular}{|c|c|c|c|c|}
\hline \multicolumn{3}{|c|}{ Residual enzyme activity (\% normal) } & \multirow{2}{*}{$P$ value } & \multirow{2}{*}{ Enhancement ratio } \\
\hline Mutation & DGJ (-) & DGJ (+) & & \\
\hline $\mathrm{M} 42 \mathrm{~V}$ & $7.2 \pm 0.22$ & $17.2 \pm 1.31$ & 0.0001 & 2.5 \\
\hline E66Q & $43.8 \pm 3.03$ & $39.3 \pm 1.26$ & NE & NE \\
\hline I91T & $12.0 \pm 0.69$ & $35.7 \pm 1.48$ & 0.0001 & 2.9 \\
\hline $\mathrm{R} 112 \mathrm{C}$ & $4.7 \pm 0.13$ & $9.3 \pm 0.60$ & 0.0001 & 2 \\
\hline $\mathrm{F} 113 \mathrm{~L}$ & $17.8 \pm 0.88$ & $47.1 \pm 1.07$ & 0.0001 & 2.6 \\
\hline C142W & $5.2 \pm 0.39$ & $7.0 \pm 0.59$ & NE & NE \\
\hline D231G & $4.4 \pm 0.32$ & $5.1 \pm 0.20$ & NE & NE \\
\hline D266N & $5.2 \pm 0.23$ & $6.4 \pm 0.67$ & NE & NE \\
\hline S297F & $5.2 \pm 0.41$ & $5.9 \pm 0.45$ & $\mathrm{NE}$ & NE \\
\hline Y86X & $5.4 \pm 0.27$ & $5.7 \pm 0.82$ & $\mathrm{NE}$ & $\mathrm{NE}$ \\
\hline
\end{tabular}

Enhancement of GLA activity by DGJ was compared in cultured COS-7 cells with a variety of mutations. The mean of each standard deviation was calculated from five independent experiments. Student T-test was used for $P$ value calculation. $P$ values below 0.05 were considered statistically significant. NE, non-enhanceable. 
A

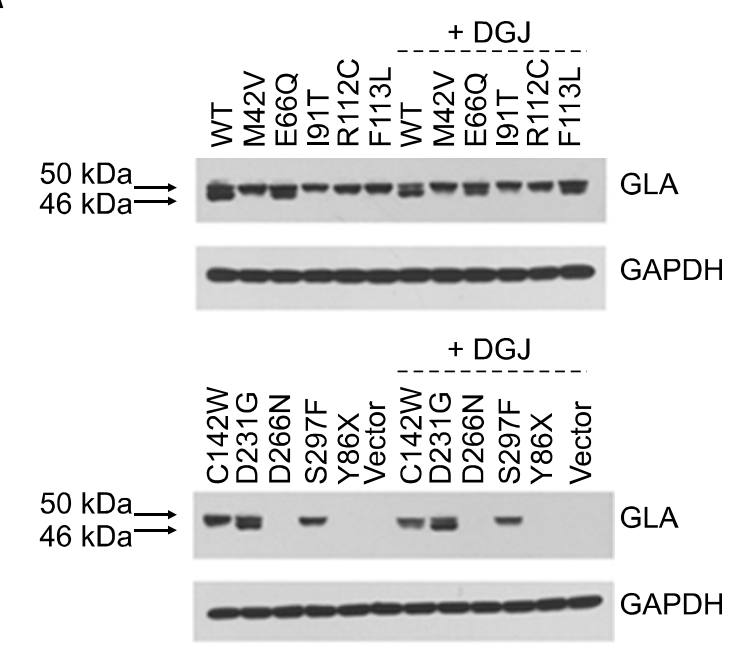

B

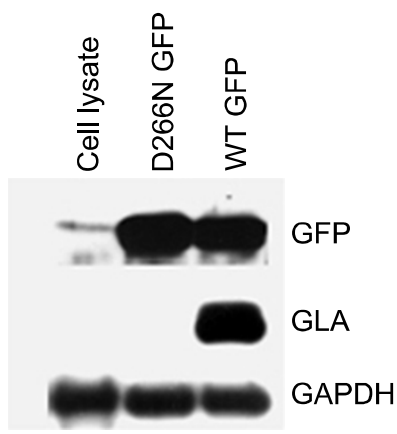

Figure 3. Western blot analysis. (A) Effect of DGJ on expression of GLA. Mutants were cultured in the presence or absence of $20 \mu \mathrm{M}$ DGJ for 2 days prior to GLA assay. (B) Protein expression of D266N mutant. GAPDH was used as an internal control.

However, the mature GLA protein was not observed in the M42V and R112C mutants.

\section{Discussion}

Enzyme replacement therapy (ERT) has proved to be an effective treatment modality for Fabry disease. Unfortunately, ERT is expensive and patients often find the frequent intravenous infusions and adverse immunological events highly inconvenient. Furthermore, the enzyme is not efficiently delivered into the central nervous system, as in other lysosomal storage diseases (LSD) involving the nervous system. One plausible treatment modality for LSD is small molecule therapy, which consists of two main strategies. The first strategy involves substrate reduction by a specific enzyme inhibitor. The other strategy, known as pharmacological chaperone therapy, involves stabilizing the
A

\begin{tabular}{lcc}
\hline & \multicolumn{2}{c}{ GLA activity } \\
\cline { 2 - 3 } & Intracellualr & Secreted \\
\hline Vector & $495 \pm 28.96$ & $67 \pm 2.81$ \\
WT & $8,359 \pm 187.42$ & $6,505 \pm 52.21$ \\
D266N & $499 \pm 42.33$ & $69.3 \pm 3.36$ \\
\hline
\end{tabular}

B

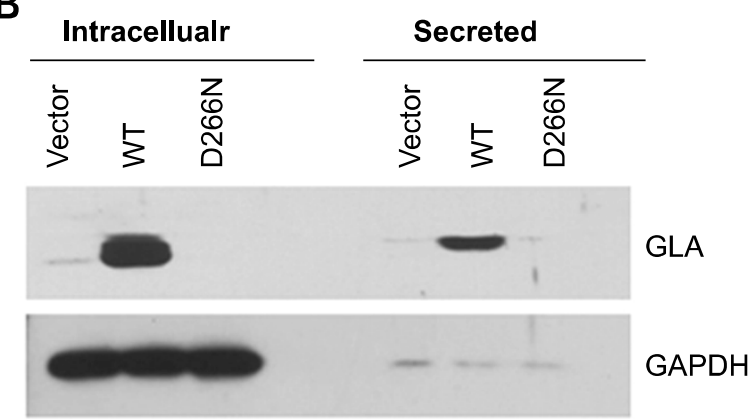

Figure 4. Enzyme activity (A) and protein expression (B) of the D266N mutant during expression in COS-7 cells. The D266N mutant was cultured in the absence of chemical chaperone for 2 days prior to enzyme assays and Western analyses. GAPDH was used as an internal control. The mean of each standard deviation was calculated from three independent experiments.

enzyme using small chemical chaperones that bind the active site of the target enzyme. In fact, pharmacological chaperone therapy has been clinically tested in the treatment of other LSDs (Matsuda et al., 2003; Tropak et al., 2004).

Galactose and its structural analog DGJ are well known chemical chaperones that bind the active site of GLA and act as competitive inhibitors (Garman and Garboczi, 2004; Fan et al., 2007). Binding promotes proper folding, dimerization, and processing of the GLA protein, thereby enhancing residual GLA activity in patients with GLA deficiencies (Frustaci et al., 2001; Matsuzawa et al., 2005; Ishii et al., 2007; Shin et al., 2007).

The active site of GLA contains side chains with residues W47, D92, D93, Y134, C142, K168, D170, E203, L206, Y207, R227, D231, D266 and M267. The $\mathrm{C} 172$ residue is connected to $\mathrm{C} 142$ via a disulfide bond (Garman and Garboczi, 2002, 2004). The active site of this enzyme is extremely sensitive to mutation: Even conservative substitutions around the active site can result in the complete loss of enzymatic activity. Furthermore, mutations can lead to folding defects in the GLA polypeptide, wherein the hydrophobic core of the protein is disrupted and the enzyme cannot fold or remain folded in the acidic lysozyme environment (Garman and Garboczi, 2002, 2004). Of the nine missense mutations explored in the present study, 
C142W, D231G and D266N are located in the enzyme's active site, while the M42V, E66Q, 191T, R112C, F113L and S297 mutations are predicted to cause folding defects in the GLA polypeptide.

Addition of DGJ to the culture medium increased GLA enzyme activity in the M42V, 191T, R112C and F113L mutants in mutation-expressing COS-7 cells. Furthermore, addition of DGJ boosted production of the mature protein in two mutations involved in the atypical form of the disease (i.e., 191T and $\mathrm{F} 113 \mathrm{~L}$ ), while production of the mature protein was not detected in two mutations involved in the classical form of the disease (i.e., M42V and $\mathrm{R} 112 \mathrm{C}$ ). These results indicated that the amount of $\mathrm{M} 42 \mathrm{~V}$ and $\mathrm{R} 112 \mathrm{C}$ protein was too low to be detected comparing with wild type. Also, the amount of protein does not always reflect its functional activity. The D266N mutation yielded particularly interesting results, considering that in vitro transient expression data detected no residual enzyme activity and CRIM findings were negative on Western blot analysis. Specific aspartate or glutamate residues function as nucleophiles in the active site of the enzyme. We hypothesize that the D266N mutation affects posttranslational glycosylation by introducing a novel site for N-glycosylation. However, as shown in Figure 4, enzyme activity and protein were not detected in cells or supernatants, suggesting that the enzyme was rapidly degraded via ERAD (ER-associated degradation) without appropriate molecular folding (Sitia and Braakman, 2003; Helenius and Aebi, 2004). Residual GLA activity was not observed in the D231G and C142W mutants, although D231G was determined to be CRIM-positive on Western blot analysis. Enzyme activity in the D231G and C142W mutants was not enhanced by DGJ, indicating that the mutation occurred in an extremely sensitive active site. Furthermore, the $\mathrm{C} 142$ residue in the disulfide bond of the enzyme's active site is strictly conserved.

No residual enzyme activities were observed in the S297F mutant and CRIM findings were positive on Western blot analysis. The GLA activity of this mutant was not enhanced in the presence of DGJ, indicating that the mutation caused a significant conformational change in the enzyme. The other novel mutation, L268delfs X1, results in premature termination and thus was not expected to yield detectable GLA activity or protein expression. Enzyme activity in the E66Q mutant was approximately $40 \%$ of the activity of wild-type GLA and the protein was expressed normally, indicating that E66Q is either a mild mutation or a functional SNP. A previous study found that the double mutation of $\mathrm{E} 66 \mathrm{Q}$ and $\mathrm{R} 112 \mathrm{C}$ eliminated enzyme activity in a transient expression assay (Ishii et al., 1992).

We screened effect of a chemical chaperone both on enzyme activity and on protein expression in various missense mutations which identified in Korean Patients with Fabry Disease. The chemical chaperone DGJ enhanced more effectively in milder mutations associated with the atypical form of Fabry disease.

\section{Methods}

\section{Patients}

To date, 13 male patients with classic Fabry disease and 2 male patients with the atypical form of the disease have been enrolled in the Korean Fabry Registry. The patients are between 13 and 48 years of age (mean $28.6 \pm 11.89$ years) and are unrelated. Diagnosis was confirmed via the GLA assay and DNA analysis of peripheral blood leukocytes. Mutations in the GLA gene were identified in all patients. This study was approved by the institutional review boards (\# 2007-9006) of Asan Medical Center, Seoul, and all patients or their parents provided written informed consent.

\section{Genomic DNA analysis}

Genomic DNA was extracted from peripheral blood leukocytes or EBV immortalized cell lines using the Puregene DNA isolation kit (Gentra). The GLA coding regions were amplified via PCR. The PCR products were directly sequenced using the BigDye termination kit, version 3.0 (Applied Biosystems), with the same primers used in the amplification reactions.

\section{Plasmid construction and mutagenesis}

The GLA cDNA used in this study was kindly provided by Genzyme. The pcDNA3 mammalian expression vector (Invitrogen) was used for the cloning of non-tagged normal GLA. Mutant GLA constructs were generated using the PCR-based Dpnl-treatment site-directed mutagenesis method as a series of base substitutions in full-length GLA cDNA of pcDNA3 (Li and Wilkinson, 1997). Mutation sites were confirmed via sequence analysis with the BigDye termination kit, version 3.0 (Applied Biosystems).

\section{Cell culture and transfection}

COS-7 cells were maintained in DMEM, supplemented with $10 \% \mathrm{FBS}, 100 \mathrm{mg} / \mathrm{ml}$ streptomycin and $100 \mathrm{U} / \mathrm{ml}$ of penicillin. Transient trasfection was performed using Lipofectamine 2000 reagent (Invitrogen) with $2 \mu \mathrm{g}$ of plasmid construct, according to the manufacturer's instructions. $1 \mu \mathrm{g}$ of pSV-B-galactosidase plasmid (Promega) was used to monitor the transfection efficiency. Cells were further incubated until harvest at $37^{\circ} \mathrm{C}$ in an atmosphere containing $5 \% \mathrm{CO}_{2}$. 


\section{DGJ treatment and GLA assays}

COS-7 cells were cultured for two days in DMEM medium, with and without $20 \mu \mathrm{M}$ DGJ (Sigma Inc., St. Louis. MO) (Fan and Ishii, 2003). Assays of GLA enzyme activity were performed using a standard fluorometric method (Desnick et al., 1973) with the following modification: Reactions containing $0.01-0.02 \mathrm{mg}$ of total protein, $10 \mu \mathrm{l}$ of $10 \mathrm{mM}$ 4-methylumbelliferyl- $\alpha$-D-galactopyranoside (i.e., substrate) and $2 \mu \mathrm{l}$ of $1 \mathrm{M} \mathrm{N}$-acetyl-D-galactosamine (i.e., an inhibitor of $\mathrm{N}$-acetylgalactosaminidase) were incubated at $37^{\circ} \mathrm{C}$ for $1 \mathrm{~h}$. All chemicals were obtained from Sigma. The reaction was stopped by adding $130 \mu \mathrm{l}$ of $0.17 \mathrm{M}$ glycine-carbonate buffer, pH 9.8. Fluorescence was detected using a fluorescence spectrophotometer (Molecular devices) with excitation and emission wavelengths of $360 \mathrm{~nm}$ and $415 \mathrm{~nm}$.

\section{Cell extracts and Western blot analyses}

Cells were homogenized in a RIPA buffer containing $1 \mathrm{mM}$ PMSF (Sigma) and Protease Inhibitor Cocktail (Roche). After centrifugation, the supernatant was used in GLA enzyme assays and Western blot analyses. Proteins were denatured using the Lowry method. For Western blot analyses, $20 \mu \mathrm{g}$ of cell extract was separated on a $10 \%$ SDS-PAGE gels and immunoblotted onto a nitrocellulose membrane (Amersham Bioscience). Membranes were blocked in TBST containing 5\% skim milk for $1 \mathrm{~h}$ at room temperature and then incubated with a 1:1,000 dilution of the GLA polyclonal antibody and the GFP monoclonal antibody (Santa Cruz, CA). Protein bands were visualized using the ECL detection system (Amersham-Pharmacia Biotech). GAPDH was used as an internal control in each Western blot analysis.

\section{Acknowledgements}

We thank the patients and their families for participating in this study, which was supported by grant No A010384 and A080588 from the Korean Ministry for Health, Welfare and Family Affairs.

\section{References}

Branton MH, Schiffmann R, Sabnis SG, Murray GJ, Quirk JM, Altarescu G, Goldfarb L, Brady RO, Balow JE, Austin lii HA, Kopp JB. Natural history of Fabry renal disease: influence of alpha-galactosidase A activity and genetic mutations on clinical course. Medicine (Baltimore) 2002;81:122-38

Desnick RJ, Allen KY, Desnick SJ, Raman MK, Bernlohr RW, Krivit W. Fabry's disease: enzymatic diagnosis of hemizygotes and heterozygotes. Alpha-galactosidase activities in plasma, serum, urine, and leukocytes. J Lab Clin Med 1973;81:157-71

Desnick RJ, Joannou YA, Eng CM. $\alpha$-galactosidase A deficiency: Fabry disease. In The Metabolic and Molecular Bases of Inherited Disease (Scriver CR, Beaudet AL, Sly WS, eds), 2001, 3733-74, McGraw-Hill, New York

Fan JQ, Ishii S. Cell-based screening of active-site specific chaperon for the treatment of Fabry disease. Methods in

\section{Enzymology 2003;363:412-20}

Fan JQ, Ishii S. Active-site-specific chaperone therapy for Fabry disease. Yin and Yang of enzyme inhibitors. FEBS J 2007;274:4962-71

Fan JQ, Ishii S, Suzuki Y. Accelerated transport and maturation of lysosomal $\alpha$-galactosidase $A$ in fabry lymphoblast by an enzyme inhibitor. Nat Med 1999;5:112-5

Froissart R, Guffon N, Vanier MT, Desnick RJ, Maire I. Fabry disease: $\mathrm{D} 313 \mathrm{Y}$ is an $\alpha$-galactosidase A sequence variant that causes pseudodeficient activity in plasma. Mol Genet Metab 2003;80:307-14

Frustaci A, Chimenti C, Ricci R, Natale L, Russo MA, Pieroni $\mathrm{M}$, Eng CM, Desnick RJ. Improvement in cardiac function in the cardiac variant of Fabry's disease with galactoseinfusion therapy. N Engl J Med 2001;345:23-32

Garman SC, Garboczi DN. Structural basis of Fabry disease. Mol Genet Metab 2002;77:3-11

Garman SC, Garboczi DN. The molecular defect leading to Fabry disease: structure of human alpha-galactosidase. $J$ Mol Biol 2004;337:319-35

Helenius A, Aebi M. Roles of N-linked glycans in the endoplasmic reticulum. Annu Rev Biochem 2004;73:101949

Ishii S, Chang HH, Kawasaki K, Yasuda K, Wu HL, Garman SC, Fan JQ. Mutant alpha-galactosidase A enzymes identified in Fabry disease patients with residual enzyme activity: biochemical characterization and restoration of normal intracellular processing by 1-deoxygalactonojirimycin. Biochem J 2007;406:285-95

Ishii $\mathrm{S}$, Sakuraba $\mathrm{H}$, Suzuki $\mathrm{Y}$. Point mutations in the upstream region of the alpha-galactosidase A gene exon 6 in an atypical variant of Fabry disease. Hum Getnet 1992; 89:29-32

Kornreich R, Desnick RJ, Bishop DF. Nucleotide sequence of the human $\alpha$-galactosidase A gene. Nucleic Acids Res 1989;17:3301-2

Lenmansky P, Bishop DF, Desnick RJ, Hasilik A, Figura KV. Synthesis and processing of a-galactosidase $A$ in human fibroblasts. J Biol Chem 1987;262:2062-5

Li S, Wilkinson MF. Site-directed mutagenesis: a two-step method using PCR and Dpnl. Biotechniques 1997;23: $588-90$

Matsuda J, Suzuki O, Oshima A, Yamamoto Y, Noguchi A, Takimoto K, Itoh M, Matsuzaki Y, Yasuda Y, Ogawa S, Sakata Y, Nanba E, Higaki K, Ogawa Y, Tominaga L, Ohno K, Iwasaki $\mathrm{H}$, Watanabe H, Brady RO, Suzuki Y. Chemical chaperone therapy for brain pathology in $\mathrm{G}(\mathrm{M} 1)$-gangliosidosis. Proc Natl Acad Sci USA 2003;100:15912-7

Matsuzawa F, Aikawa SI, Doi H, Okumiya T, Sakuraba H. Fabry disease: correlation between structural changes in a-galactosidase, and clinical and biochemical phenotypes. Hum Genet 2005;117:317-28

Okumiya T, Ishii S, Takenaka T, Kase R, Kamei S, Sakuraba $H$, Suzuki Y. Galactose stabilizes various missense mutants of alpha-galactosidase in Fabry disease. Biochem Biophys 
Res Commun 1995;214:1219-24

Peter FP, Sommer A, Vermeulen A, Cheriex EC, Kho TL. Fabry's disease: a multidisciplinary disorder. Postgrad Med J 1997;73:710-2

Shin SH, Murray GJ, Kluepfel-Stahl S, Cooney AM, Quirk JM, Schiffmann R, Brady RO, Kaneski CR. Screening for pharmacological chaperones in Fabry disease. Biochem Biophys Rec Commun 2007;359:168-73

Sitia R, Braakman I. Quality control in the endoplasmic reticulum protein factory. Nature 2003;426:891-4

Tropak MB, Reid SP, Guiral M, Withers SG, Mahuran D. Pharmacological enhancement of beta-hexosaminidase activity in fibroblasts from adult Tay-Sachs and Sandhoff Patients. J Biol Chem 2004;279:13478-87

Yam GH, Bosshard N, Zuber C, Steinmann B, Roth J. Pharmacological chapherone corrects lysosomal storage in Fabry disease caused by trafficking-incompetent variant. Am J Physiol Cell Physiol 2006;290:1076-82 